EPHEMERIS OF THE SATELLITES OF MARS FOR THE OPPOSITION OF 1881.*

\author{
BY H. S. Pritchett.
}

Owing to the greater distance from the Earth and the Sun, the present opposition of Mars will not be so favorable as the two preceding ones; still these distances will be sufficiently small to permit many useful observations of physical phenomena, and, in the case of large telescopes, observations of the satellites. In one respect, the planet is much more favorably situated than in the former oppositions referred to, since it reaches this year a declination of $26^{\circ}$ north, and hence will be observed at a much higher altitude. Physical observations, either measures or drawings, by amateur astronomers with good glasses, if carefully made and published, will be useful when finally reduced and compared.

During the last opposition several series of micrometric measures of the diameter of the planet were made by observers with good telescopes which showed curious differences buth between themselves and when compared with the results obtained from the heliometer. Some of these measures seemed to show an appreciable flattening at the poles, while others showed no such flattening. It will be interesting to have these measures repeated during the present opposition, with a careful discussion of the sources and effects of personal error.

The satellites were observed last opposition with at least one of the large reflectors, with the great refractor at Washington, with the 15-inch refractor of the Harvard College Observatory, and with the 12!' inch refractor of the Morrison Observatory, and were seen with other instruments. Before December ist of this year the satellites will be consillerably brighter than when last observed in 1879 with the Harvard Collegre refractor, and also brighter than when last observed with the Morrison Oisservatory refractor. It seems possible, therefore, that they may be seen this year with telescopes even of moderate size.

The following ephemeris (derived from the elements of Prof. A. Hall, A. N. No. 2394) has been computed at the requ:st of several ob iervers, and will be found convenient for any who may wish to observe these satellites. In connection with the discussion of the relative merits of reflectors and refractors, excited by the observations of these satellites, it may be interesting to many to try if they can see them.

In the case of Deimos, the outer satellite, the ephemeris gives the Washington mean times of the east and west elongations, together with the position-angle and distance at the time of elongation. In the case of I'hobos on.y the times of western elongations are given, as the revolution time is very short and the times of eastern elongations may be obtained by a simple interpolation. The aberration time is not included in the time gillen, but it may be taken from the table at the end if desired, the effect of the aberration being to make the satellites about five minutes late at each elongation. The relative brightness on different days may be obtained from the same table, taking the brightness on Nov. 20 as unity. As was shown iyy the observations of 1879 , Prof. Hall's elements are very nearly correct, so that the correction to this ephemeris will be quite small.

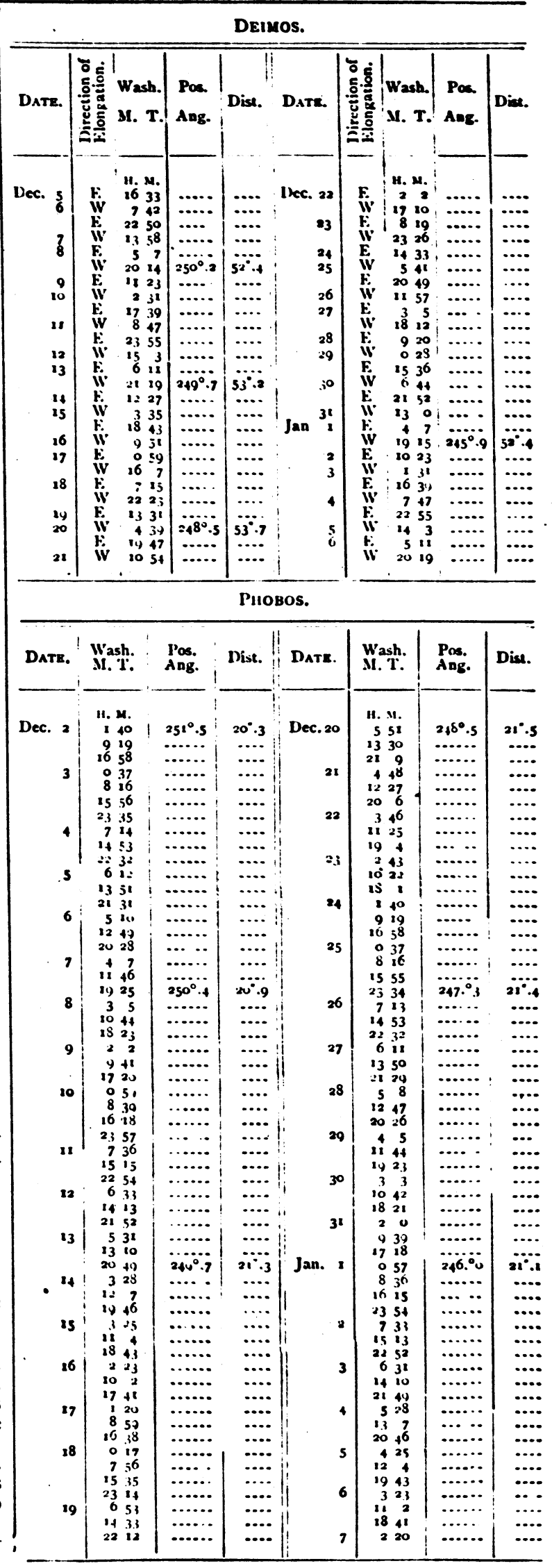




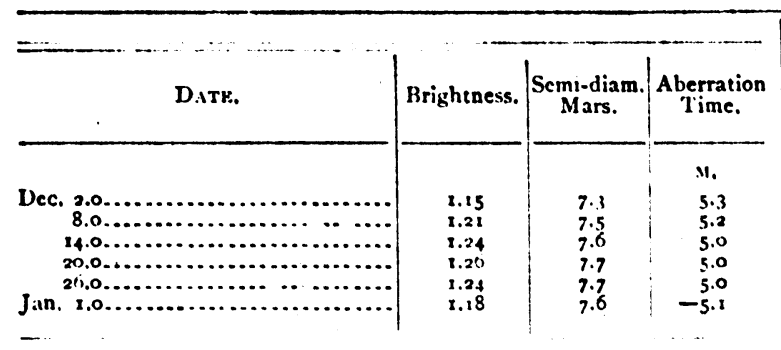

From this it will be seen that Phobcs, even on the most favorable date, will be only about 14 " distant from the limb of the planet. In 1877 this satellite was observed with the 1214 equatorial of the Morrison Observatory when only $7^{\prime \prime}$ distant. In the present opposition the satellite will be much fatinter. I ut on the other hand the: brightness of the planet will he considerably diminished. It seems possible, therefore that this sattellite may be seen with glasses of moderate size.

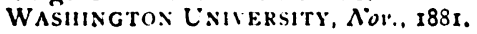

\section{ELEMENTS OF QUATERNIONS.*}

BY A. S. HAkUy, Ph. 1)., I'rofe'ssor of Ma hematics, Dartrouth College.

The American press may be expected to teem for the next twenty-five jears with elementary treatises on quaternions, and as this work of Professur Hardy's is, We believe, the first of the series, it merits on this account the more attention. The book has a quite neat and attractive exterior, and the mechanical execution is very fair, though a few defects in letter press and engraving are noticeable. The experiment of printing small $A l p h a s$ with an oblicue line through them seems to be a failure. Serp p) 45 and ro.

We cammot think the title happily chosen. There is an incongruity, if not positive impropriely, in assigning 10 a sciant text-book intended for begimners in the class-room a name associated these tifteen years with the great and classic work of Hamilton. This however, is a matter of taste. One of the most important and difficult steps in the logical development of the calculus of quaternions, to which their inventor gave no little atiention, is that of assigning a versor power to a vector, or of representing rotation by a symbol that had hitherto been appropriated exclusively to vection or translation. This, in the book before us, is disposed of in a few lines, when, even in a treatise where brevity must be studied, it is well worthy of as many pages. i ihere is, also, throughout the work, an unfortunate fondness for the plane, where quaternions are often at a disadvantage, and where their real power ar:d usefulness cannot be exhibited. The au:hor may have intended to thus avail hiniself of the student's greater familiarity with the geometry of the plane, while introducing him to a new method: but it ought to be borne in mind that one of the chief claims quaternions have on the teacher of geometry is that they are specially fitted to free the student from the too prevalent restric. tion of his conceptions to two dimensions. $\Lambda$ curious example of this tendency of the book is atforded near the end in applications to loci. Here the author systematically interprets ciguations as relating to the conic sections, when in reality they frequently relate to quadrics of revolution, the restriction to plane loci having been eliminated in the process of their formation; and when he comes " to transform the proceeding equations into the usual cartesian forms," instead of substituting a trinomial for the variable vector, he imposes a restriction to two dimensions by adopting a binomial, and of cuurse comes out with a plane section in place of the surface itseif. Notwithstanding these imperfections, Prof. Hlardy has evi-

$* 8^{\circ}$, pp. VIll, $23^{\circ}$. Boston, Ginn, Heath \& Co., 188r. dently studied his subject and written his book with some care, and with a view to the requirements and opportunities of those for whom it is intended, and it will dcubtless prove useful as an introduction to quaternions.

\section{U.S. COAST S GeODETIC SURVFY,} ALEX. S. ChRISTIE.

\section{I.ARGE: TELLSCOPES.}

PRoressur limarn C. PICKERIN(; makes the following suggestion in regard to mounting a telescope on a new plan. He sajs:- "The small amount of work accomplished with large telescopes has often been the subject of unfariorable comment, This criticism applies with especial force in Americia, where there are nearly a doren eckescopess hatring an apereture of a foot or over, hesicles (w) of the largest size now in course of construction, and two of ewenty-six and twenty-four inches aperture which are unmounted and have been for several years perfectly useless. Among so many it seems as if one might be spared for a trial of the following plan, which, if successful, would produce at a small expense far more work than could be obtained with a mounting of the usual form.

Suppose that the telescope is placed horizontally at right angles to the meridian, and that a plane reflector inclined to its axis by $+5^{\circ}$ is placeel in front of it. This reflector may revolie around an axis coincidling with that of the telescope. Such a mounting has been used in transit instruments, and gives much satisfaction in the meridian photometer of the Harvard College (observatory. The principal difficulty with a large instrument would lie in the flexure of the reflector. This difficulty has, however, been overcome in a great measure in reflecting telescopes by various ingenious devices. In the present case, since the refleetor rotates only around one axis instead of two. the problem is much simplitied. A slight motion at right imerles of perhatps 5 " would be at great combenience. as will he shown below, amel would probuldy be insulficient to matterially affect the llexure. It maty be sitid that it is more diftecult to make a plane surface than one that is curved. liut the principal effect of a slight curvature would be to changre the focus of the telescope, the aberration being much less than the effect of the varying thexure. I.et us admit, however, that the best definition cannot be obtained, in considering the purposes to which such an instrument could be applied without disadiantage.

Many adrantages will be apparent on comparing such a mounting with an equatorial. Great steadiness would be secured, since the mirror would be the only portion moved, and this would be placed directly upon a low pier. Instead of a large and expensive dome which is moved with difficulty, the mirror would be protected by a small shed, of which the roof could be easily removed. It would therefore be opened and ready for use in a very short time, and would quickly take the temperature of the surrounding air. The object-glass woukd be mounted directly upon a second pier, and, as it would not be moved, would be in very little danger of accident. The tube could be made of tin or other inexpensive material. as Its flexure is of no importance. It could easily be protected from the chamges of the temperature so troublesome in the tube of a large equatorial. If preferred it might even be exhausted of air. or tilled with hydrogen. and the effect of the changes of temperature thus greatly reduced.

The eyepiece could be mounted on a third pier, and would be so far distant horizontally from the mirror and object-glass that there is no reason that it should not be inclosed in a room which may be warmed. The comfort in winter of working in a warm room will be appreciated by those who have used a large telescope in a cold climate. The result is sure to be an increased precision in 